\title{
kdsA mutations affect FtsZ-ring formation in Escherichia coli K-12
}

\author{
H. Fujishima, ${ }^{1}$ A. Nishimura, ${ }^{1}$ M. Wachi, ${ }^{2}$ H. Takagi, ${ }^{1}$ T. Hirasawa, ${ }^{2}$ \\ H. Teraoka, ${ }^{2}$ K. Nishimori, ${ }^{1}$ T. Kawabata, ${ }^{1}$ K. Nishikawa ${ }^{1}$ and K. Nagai ${ }^{2}$
}

Author for correspondence: A. Nishimura. Tel: +81559 81 6827. Fax: +81559816826.

e-mail: anishimu@lab.nig.ac.jp

\footnotetext{
1 National Institute of Genetics, Mishima, Shizuoka-ken 411-8540, Japan

2 Department of Bioengineering, Tokyo Institute of Technology, Midori-ku, Yokohama 226-8501, Japan
}

\begin{abstract}
No one has, as yet, addressed the relationship between the nature of the outer membrane and cell division. $k d s A$ encodes 3-deoxy-D-manno-octulosonic acid (KDO) 8-phosphate synthetase which catalyses the first step in the synthesis of KDO, the linker between lipid $A$ and oligosaccharide of lipopolysaccharide (LPS). Seven temperature-sensitive mutants containing missense mutations in $k d s A$ were affected in the production of KDO and all mutants stopped dividing at $41^{\circ} \mathrm{C}$ and formed filaments with either one or no FtsZ ring. All observed defects were reversed by the plasmid-borne wild-type $k d s A$ gene. Western blotting analysis, however, demonstrated that the amount of FtsZ protein was not affected by the mutation. The mutants were more susceptible to various hydrophobic materials, such as novobiocin, eosin $Y$ and SDS at $36{ }^{\circ} \mathrm{C}$. Methylene blue, however, restored kdsA mutant growth. Plasmid-borne wildtype msbA, encoding a lipid A transporter in the ABC family, partially suppressed $k d s A$ mutation. A mutation of IpxA, functioning at the first stage in lipid A biosynthesis, inhibited both cell division and growth, producing short filaments. These results indicate that the instability of the outer membrane, caused by the defect in KDO biosynthesis, affects FtsZ-ring formation.
\end{abstract}

Keywords: $k d s A$ mutants of $E$. coli, KDO biosynthesis, membrane structure, cell division, lipopolysaccharide synthesis

\section{INTRODUCTION}

The outer membrane of Gram-negative bacteria, such as Escherichia coli, plays a central role in controlling the interaction of the bacteria with the external environment, serving as a barrier, controlling the absorption of ions and nutrients and transmitting signals to the inside of the cell. Instabilities of the outer membrane adversely affect multiple cellular responses. Proper cell division requires both the construction of division machinery, physically separating internal cellular components, and the division of cell membrane structures. Both processes are closely related; instabilities in membranes may affect both the construction of division machinery and the expression of gene(s) essential for cell division. However, the mechanism controlling the relationship between cell division and the nature of the cell membrane remains unknown. We have created seven unique $f t s / k d s A$ mutants allowing analysis of the discrimi-

Abbreviations: DAPI, 4',6-diamino-2-phenyl-indole; KDO, 3-deoxy-Dmanno-octulosonic acid. nation mechanism governing membrane construction and cell division.

The outer membrane of Gram-negative bacteria is composed principally of lipopolysaccharide (LPS) and phospholipids. LPS comprises approximately $30 \%$ of the outer membrane by gross weight (Smit et al., 1975). LPS, comprising hydrophobic lipid A, the hydrophilic core oligosaccharide chain and 3-deoxy-D-manno-octulosonic acid (KDO), connecting lipid A to the oligosaccharide chain (Raetz et al., 1985; Rietschel, 1984), is important in determining outer-membrane barrier function (Leive, 1974; Nikaido \& Vaara, 1985).

$\mathrm{KDO}$ is synthesized by the condensation of $\mathrm{D}$-arabinose5-phosphate and phosphoenolpyruvate, followed by dephosphorylation. The first step of the reaction is catalysed by KDO 8-phosphate synthetase, encoded by the $k d s A$ gene in both Salmonella typhimurium (Rick et al., 1977) and E. coli (Ray, 1980). E. coli kdsA, however, was first identified as a gene complementing the $k d s A$ mutation of Salmonella (Woisetschläger \& Högenauer, 1987), although no similar mutants have yet been identified in E. coli. Mutations in $k d s A$ of Salmonella 
typhimurium cause the accumulation of lipid A in the periplasm, also resulting in the disappearance of LPS from the outer membrane (Rick \& Osborn, 1977; Osborn et al., 1980). LPS is an essential membrane component (Strohmaier et al., 1995) and only conditional lethal mutants in KDO biosynthesis can be isolated in Salmonella (Lehmann et al., 1977; Rick et al., 1977; Rick \& Young, 1982). The biosynthesis of LPS is growth-phase-regulated at the transcriptional level in $E$. coli (Strohmaier et al., 1995); no evidence, however, has uncovered a relationship between LPS biosynthesis and cell division. In this study, we isolated temperaturesensitive mutants of $k d s A$ and demonstrated that membrane instability resulting from the defect in KDO biosynthesis affected the FtsZ-ring formation.

\section{METHODS}

Bacterial strains and bacteriological procedures. The E. coli strains used in this paper are catalogued in the NIG collection (http://shigen.lab.nig.ac.jp/ecoli/strain/). L broth contained $1 \%$ tryptone, $0.5 \%$ yeast extract, $0.5 \% \mathrm{NaCl}$ and $0.1 \%$ glucose. The $\mathrm{pH}$ was adjusted to $7 \cdot 0$ using $1 \mathrm{M} \mathrm{NaOH}$. Thymine was added to media at a concentration of $100 \mu \mathrm{g} \mathrm{ml}^{-1}$. Tetracycline, when needed, was utilized at a concentration of $20 \mu \mathrm{g} \mathrm{ml}^{-1}$. Transduction with P1 and T4GT7 phages was performed as described by Buxton \& Holland (1973) and by Wilson et al. (1979), respectively. Selection plates used for P1-phage-mediated transduction contained $1 \%$ sodium citrate. Cell number was monitored with a Coulter multisizer II (Coulter Electronics) equipped with a $30 \mu \mathrm{m}$ orifice and accommodating a volume of $100 \mu \mathrm{l}$.

Fluorescence microscopy. To observe cells and nucleoids by microscopy, cells were stained by 4',6-diamino-2-phenylindole (DAPI) as described by Hiraga et al. (1989). Localization of FtsZ was visualized by immunofluorescence microscopy, as described by Hiraga et al. (1998) using a rabbit anti-FtsZ antibody, kindly provided by Dr J. Lutkenhaus (Addinall et al., 1996), as the first antibody and Cy3-labelled anti-rabbit IgG antibody as a second antibody.

Site-directed mutagenesis. We constructed a plasmid by sitedirected mutagenesis substituting a $\mathrm{G}$ and A for T696 and G699 of $k d s A$, respectively, carried by pTN18H. We designed four primers to prepare PCR products containing either the $5^{\prime}$ or $3^{\prime}$ half of $k d s A$ using pTN18H as the template. The sequence of the forward primer to amplify the $5^{\prime}$ half region of $k d s A$ was 5'-TCATCGATAAGCTTTAATGCGGTAG-3', homologous to the HindIII flanking region of pTN18H. The sequence of the reverse primer was 5'-AGCCCCGCTAGCCCTACC-3', the complementary sequence from G690 to T707 of $k d s A$ containing the T696G and G699A substitutions. The resulting PCR products contained both the 2 base substitutions and an additional NheI site, 5'-GCTAGC-3'. To amplify the $3^{\prime}$ region of $k d s A$, the forward primer sequence $5^{\prime}$ GCGGTAGGGCTAGCGGGGC-3' was used to create 2 base substitutions and an NheI site. The reverse primer $5^{\prime}$ CGCGCGAGGCAGCTGCGGTAA-3' contained the PvuII flanking region of $\mathrm{pBR} 322$, the parent vector of $\mathrm{pTN} 18 \mathrm{H}$. The PCR product, containing the $5^{\prime}$ half region, was cut by NheI and HindIII; the $3^{\prime}$ half region was cut by NheI and PvuII. Both were ligated to the $2 \mathrm{~kb}$ HindIII-PvuII fragment of pBR322 concurrently. The resulting plasmid, pTN18HX, was used for the complementation test of the $f t s$ mutants.

Quantitative analysis of KDO. Quantitative analysis of KDO was performed as described by Karkhanis et al. (1978) with the following modifications. Cultures growing exponentially $(0 \cdot 2$ $\left.\mathrm{OD}_{600}\right)$ in L-broth at $30^{\circ} \mathrm{C}$ were diluted 1- to 150 -fold with fresh medium [for JE10830/p $\left(k d s A^{+}\right) 10 \mu \mathrm{M}$ IPTG was added] and incubated at $41^{\circ} \mathrm{C}$ for $0 \cdot 5,1,2$ and $3 \mathrm{~h}$, respectively. At each time point, $\mathrm{OD}_{600}$ was measured, the values of which were corrected for the dilution factors and are shown relative to the value of the $0 \mathrm{~h}$ sample. This makes it possible to give the same nutritional condition for each point of analysis. Cells were harvested from $12 \mathrm{ml}$ of each culture and washed twice with $0.5 \mathrm{ml} 10 \mathrm{mM}$ HEPES ( $\mathrm{pH} \mathrm{7.4)}$ by centrifuging at 3500 r.p.m. for $10 \mathrm{~min}$. Cells were broken with an Ultrasonic Cleaner USC-1 (Pasorina) for $30 \mathrm{~s}$ in an Eppendorf tube. A $10 \mu \mathrm{l}$ aliquot of the sample was utilized to quantify the total proteins. We added $60 \mu \mathrm{l} 0.9 \mathrm{M} \mathrm{H}_{2} \mathrm{SO}_{4}$ to the remaining sample and boiled in a water bath for $40 \mathrm{~min}$ to separate the KDO from LPS. Samples were allowed to cool to ambient temperature, then centrifuged at 15000 r.p.m. for 5 min. A $0 \cdot 25 \mathrm{ml}$ aliquot of the supernatant was transferred to a new tube, $125 \mu \mathrm{l} 40 \mathrm{mM} \mathrm{HIO}_{4}$ was then added and incubated at room temperature for $20 \mathrm{~min}$ to form $\mathrm{KDO}-\mathrm{COOH}$. After 5 min incubation with $125 \mu \mathrm{l} 2.6 \% \mathrm{NaAsO}_{2}$ in $0.5 \mathrm{M} \mathrm{HCl}$, $250 \mu \mathrm{l} 0 \cdot 6 \%$ TBA was added. Samples were then boiled for $15 \mathrm{~min}$. Following the addition of $500 \mu \mathrm{l}$ undiluted DMSO, the $\mathrm{OD}_{548}$ was measured. Purified KDO (Sigma) was used as a standard.

Construction of plasmids. A $2 \cdot 3 \mathrm{~kb}$ DNA fragment containing intact $m s b A$ was amplified from genomic DNA of the wildtype strain MG1655 by PCR using a pair of primers: $5^{\prime}$ CAGGCAACATTGCTTCAGGATCCTC-3' and 5'-CAGCCTTACCACCGGATCCCCGCGA-3'. Amplified DNA was digested with Bam HI and then cloned at the BamHI site on the vector plasmid pMW118 (Nippon Gene Co.). One of the resulting plasmids, in which the $m s b A$ gene is located downstream of the lac promoter on the vector plasmid in the same direction, was named as pMsbA.

Western blotting. Western blotting was performed as described by Sambrook et al. (1989). Pelleted cells were resuspended in $100 \mu \mathrm{l}$ SDS sample buffer to give $1 \mathrm{OD}_{600}$ unit, then boiled for $3 \mathrm{~min}$. Ten microlitres of each sample was electrophoresed on a $10 \%$ SDS polyacrylamide gel, transferred to membranes and immunostained using an anti-Fts $Z$ polyclonal antibody. The anti-FtsZ polyclonal antibody was kindly provided by Dr J. Lutkenhaus. Western blots were visualized using an ECL Western blotting kit (Amersham). The resultant membranes were exposed to X-ray films.

\section{RESULTS}

\section{Effects of the seven fts mutations on cell growth}

Some $356 \mathrm{fts}$ mutants, screened from 'Hirota's temperature-sensitive mutant bank' and defective in septation, were roughly mapped by complementation (Nishimura et al., 1991) using the bank of 2200 E. coli strains carrying pLC-plasmids (Clarke \& Carbon, 1976). Seven of these fts mutants, JE10446, JE10705, JE10830, JE11167, JE11171, JE11212 and JE11241, were defined as carrying mutations in new genes involved in cell division because they were complemented by the pLC1327 plasmid, carrying the $27 \mathrm{~min}$ region of the E. coli chromosome (Nishimura et al., 1992). This region does not contain any of the known fts genes and hence the seven $\mathrm{fts}$ mutants were chosen for further study.

We examined the effects of the fts830 mutation on cell division and growth. Cultures of both JE10830 and the 


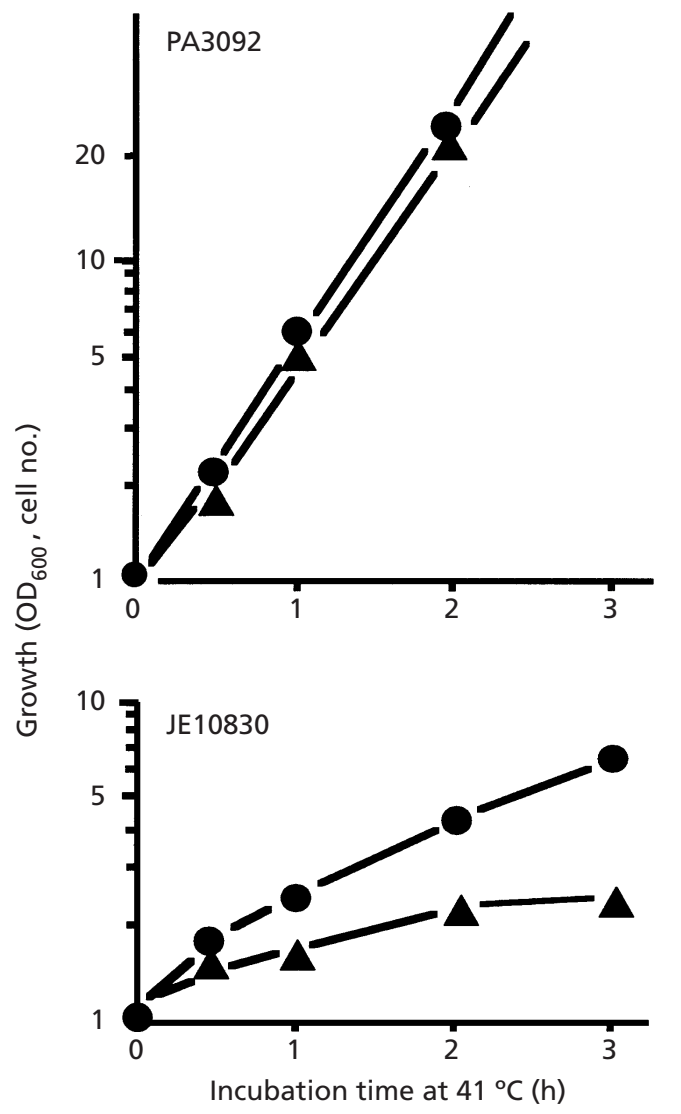

Fig. 1. Growth curve. JE10830 and parent cells (PA3092), growing exponentially at $30^{\circ} \mathrm{C}$, were diluted and grown at $41^{\circ} \mathrm{C} . \mathrm{OD}_{600}(\boldsymbol{O})$ and cell number $(\boldsymbol{\Delta})$ were monitored at the indicated times, relative to that at time zero.

parent bacterium, PA3092, growing exponentially at $30^{\circ} \mathrm{C}$, were diluted to $5 \times 10^{7}$ cells $\mathrm{ml}^{-1}$ and incubated at $41^{\circ} \mathrm{C}$. We monitored cell numbers utilizing a Coulter counter and cell growth as $\mathrm{OD}_{600}$. The $\mathrm{OD}_{600}$ of JE10830 bacteria continued to increase after the temperature shift, although the increase was lower than that of the wild-type strain. Cell division, however, stopped completely $2 \mathrm{~h}$ after the temperature shift to $41^{\circ} \mathrm{C}$ (Fig. 1). DAPI staining demonstrated that chromosomal replication and segregation appeared normal for at least $3 \mathrm{~h}$ at $41{ }^{\circ} \mathrm{C}$ (Fig. 2). We examined the six remaining strains similarly, using the same medium, LB containing $0.5 \%$ $\mathrm{NaCl}$. JE10446, JE11171, and JE11241 demonstrated similar phenotypes to JE10830 (data not shown). JE10705 and JE11212 appeared to have a leaky phenotype since cell number per $\mathrm{OD}_{600}$ after $3 \mathrm{~h}$ incubation at $41^{\circ} \mathrm{C}$ was about three times more than that of JE10830. Cells, however, stopped dividing completely at $41^{\circ} \mathrm{C}$ when grown in $\mathrm{LB}$ medium without $\mathrm{NaCl}$. Many cell division mutants recover cell division when the growth medium has an $\mathrm{NaCl}$ concentration higher than a critical concentration specific to a mutation due to osmotic effects (Reeves et al., 1970; Ricard \& Hirota, 1973). The critical concentration of $\mathrm{NaCl}$ for these two strains may be lower than $0.5 \%$.
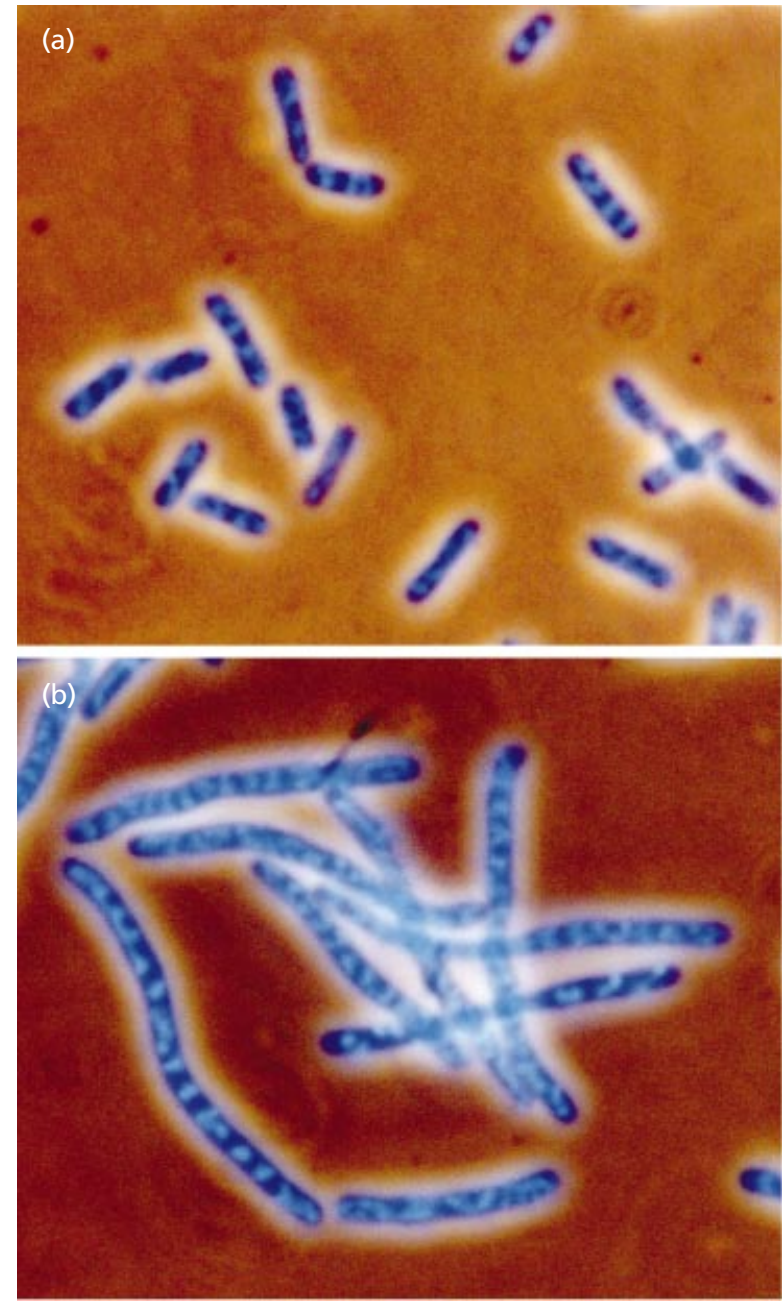

Fig. 2. Nucleoid localization in JE10830 cells. DAPI-stained phase fluorescence micrographs are shown for JE10830 grown for $3 \mathrm{~h}$ at either $30(\mathrm{a})$ or $41^{\circ} \mathrm{C}(\mathrm{b})$.

\section{Seven $f t s$ mutants have mutations in the $k d s A$ gene}

We performed P1-phage-mediated transduction to verify that the $f t s 830$ mutation lies at approximately $27 \mathrm{~min}$ within the E. coli genetic map and that pLC13-27 does not contain a multicopy suppressor. The temperaturesensitive phenotype of JE10830 was eliminated by cotransduction of either $\operatorname{trp}:: \operatorname{Tn} 10$ or $\mathrm{fadR}:: \operatorname{Tn} 5$ with an efficiency of $13.0 \%$ and $23.8 \%$, respectively, using P1 phage. On the contrary, the fts 830 mutation was cotransduced out with $\operatorname{trp}::$ Tn10 into the wild-type strain, MG1655, with a similar efficiency using T4GT7 phage. The six other mutations were also co-transduced with $\operatorname{trp}:: \operatorname{Tn} 10$ and $\operatorname{fadR}:: \operatorname{Tn} 5$ with similar efficiencies.

To clone the wild-type $f t s 830$ gene, we constructed the plasmids pTN18 and pTN23 by insertion of the $4.8 \mathrm{~kb}$ SspI segment of pLC13-27 into the EcoRV site within pBR322 in both directions. As shown in Fig. 3(a), both plasmids complemented the fts830 mutation. After testing subclones containing various deletions for their ability to complement $\mathrm{fts} 830$, we determined that a 
a)

pLC13-27
pTN18
(pTN23:
inverted pTN18)
pTN23E
pTN23H
pTN18B
pTN23B
pTN18E
pTN18H
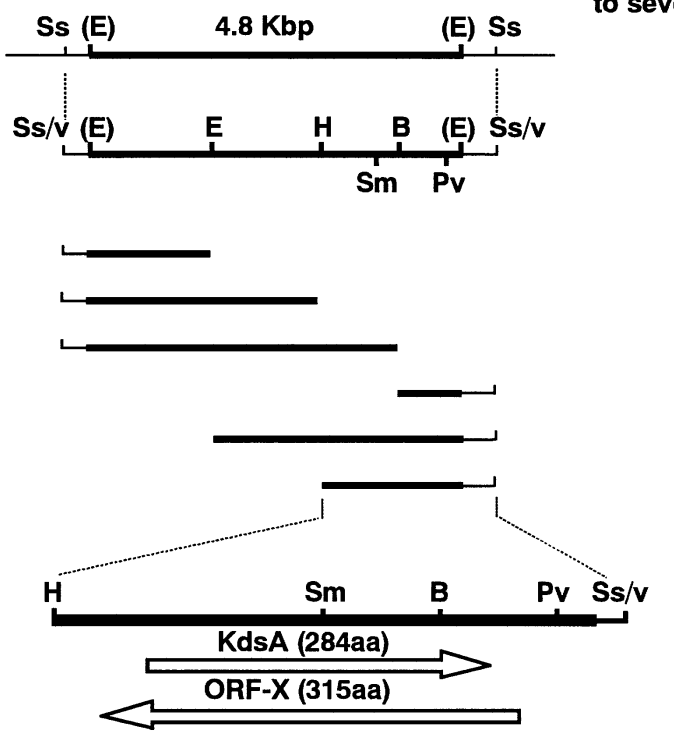

b)

(pTN18H)

pTN18HX

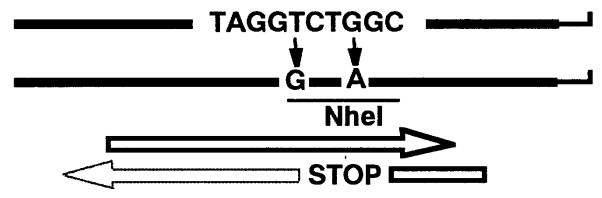

complementation

to seven fts mutants

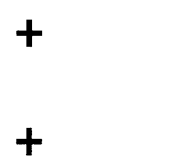

Fig. 3. (a) Complementation analysis of seven fts mutants using $\mathrm{pLC} 13-27$ and the subcloned plasmids. pTN18 carries a $4.8 \mathrm{~kb}$ Sspl segment of pLC13-27 in the EcoRV site of pBR322, and pTN23 carries the same segment in the opposite orientation. pTN18B $(E, H)$ and pTN23B $(E, H)$ lack BamHI (EcoRI, HindIII) fragments from pTN18 and pTN23, respectively. The chromosomal region (thick bar) surrounding $k d s A$ and selected restriction sites are shown schematically. Right and left directional open arrows denote KdsA and ORF-X, respectively. + denotes the effective growth of transformed cells at $41{ }^{\circ} \mathrm{C}$; - signifies that cells were unable to grow at this temperature. (b) Bases altered by sitedirected mutagenesis are shown schematically. The thin bar and STOP denotes the created Nhel restriction site and the stop codon, respectively. The dotted arrow denotes the untranslated region of ORF-X.

a) fts1167 $\begin{array}{r}830 \\ 1241\end{array}$

44612121171

Mutations

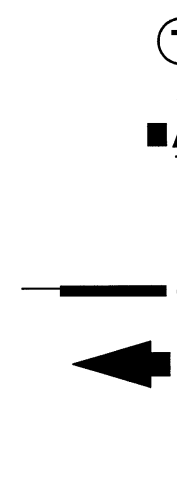

(T) $\mathbf{v}$ 444

A. AlA

a $t$
KdsA

$\stackrel{a}{g} \quad \stackrel{a}{a}=c$

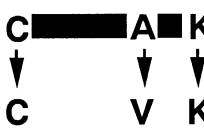

$\begin{array}{cc}A=K \\ \downarrow \\ V & K\end{array}$ $k d s A$

4

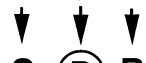

C (D) $R$

ORF $X$
C口GロR

b)

1.62

$3.28 \quad 2.23$ 3.33
3.282 .253 .18
Relative average cell length
Fig. 4. (a) Mutation sites and expected amino acid changes of the seven fts mutants. The thin bar denotes the chromosomal region surrounding $k d s A$. Small arrows with lower case letters denote that the original bases have been mutated to the top bases. The right directional thick arrow and the left arrow indicate KdsA and ORF-X, respectively. Small arrows with capital letters denote that the expected amino acids are changed to the top or bottom amino acids by the mutation; circled capital letters indicate stronger polarity changes. (b) Relative average cell length. The mutant cells were grown at $41^{\circ} \mathrm{C}$, as in Fig. 1. At 0 and $3 \mathrm{~h}$, phase-contrast micrographs were taken, and average cell length was measured. The relative increase of average cell length against the $0 \mathrm{~h}$ sample is indicated. Larger values demonstrate a greater inhibition of cell division.
$1.5 \mathrm{~kb}$ HindIII-PvuII segment, carried by the pTN18H plasmid, which lacks $3.3 \mathrm{~kb}$ of the original $S s p \mathrm{I}$ fragment, complemented $\mathrm{fts} 830$. Sequencing analysis demonstrated that this segment contained both $k d s A$ and ORF-X, on the opposite strand. ORF-X may encode a protein composed of 315 aa. The six remaining $f t s$ mutants were also complemented by the pTN18H plasmid.

We isolated and sequenced PCR products from this region using genomic DNA of mutants as a template. All seven mutants contained missense mutations in $k d s A$, causing the expected amino acid substitutions (Fig. 4a). No amino acid changes were found, however, in the ORF-X sequence of four mutants, JE10446, JE10705, JE11167 and JE11171. Strong polarity changes of amino acid substitutions in KdsA of the mutants resulted in greater inhibition of cell division, as seen with the JE10446, JE10830, JE11171 and JE11241 mutants, although JE11167 was an exception (Fig. 4b).

To confirm the phenotype of the mutants was caused by 


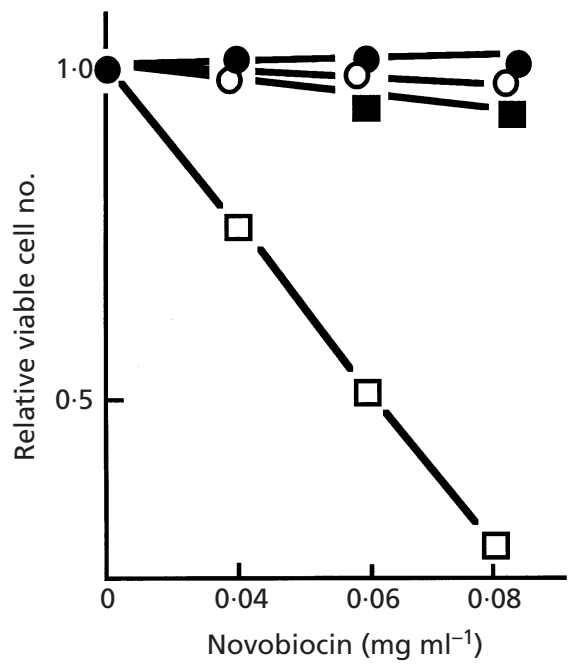

Fig. 5. Effect of $\mathrm{fts} 830$ on sensitivity to novobiocin. JE10830 and the parent, PA3092, growing exponentially at $30^{\circ} \mathrm{C}$, were diluted and spread on LB-agar medium containing variable concentrations of novobiocin. Following incubation at 30 or $36{ }^{\circ} \mathrm{C}$ for $36 \mathrm{~h}$, the number of colonies was counted. P, PA3092 at $30{ }^{\circ} \mathrm{C} ; \mathrm{O}, \mathrm{PA} 3092$ at $36{ }^{\circ} \mathrm{C} ; \mathbf{\square}, \mathrm{JE} 10830$ at $30{ }^{\circ} \mathrm{C} ; \square, \mathrm{JE} 10830$ at $36^{\circ} \mathrm{C}$.

mutations in $k d s A$, not ORF-X, we constructed a plasmid, pTN18HX, through site-directed mutagenesis, altering T696 and G699 of $k d s A$ to $\mathrm{G}$ and A, respectively (Fig. 3b). These base substitutions do not alter the KdsA amino acid sequence, but change the 70th glutamic acid of ORF-X to a nonsense codon. The plasmid complemented all seven $\mathrm{fts}$ mutants, displaying colony formation at $41^{\circ} \mathrm{C}$. These results suggest that the seven $\mathrm{fts}$ mutations are alleles of $k d s A$.

We found recently that the $t s 20$ mutant, defective in cell division at the restrictive temperature (Nagai \& Tamura, 1972), carried the same allele as $f t s 705$.

\section{The $k d s A$ mutations affect KDO production and sensitivity to hydrophobic materials}

LPS serves as a barrier against hydrophobic materials and mutations involved in LPS synthesis result in an increased sensitivity to hydrophobic materials (Hancock \& Reeves, 1976). To examine membrane stability, we compared the sensitivity of both the mutants and the wild-type strain to hydrophobic drugs. Exponentially growing cultures of both JE10830 and the parent, PA3092, were diluted and plated on LB medium containing variable concentrations of novobiocin, a hydrophobic antibiotic inhibitor of the $g y r B$ protein (Drlica, 1984). Incubation was carried out at $36^{\circ} \mathrm{C}$, the maximum temperature at which the mutants were able to form colonies. The colony-forming ability of JE10830 decreased inversely with increasing concentrations of novobiocin; growth of the parent strain was not affected (Fig. 5). We also examined the effects of other substances on mutant growth. Cultures of the JE10830 mutant and the parent strain were diluted to $5 \times 10^{5}$ cells ml$^{-1}$,

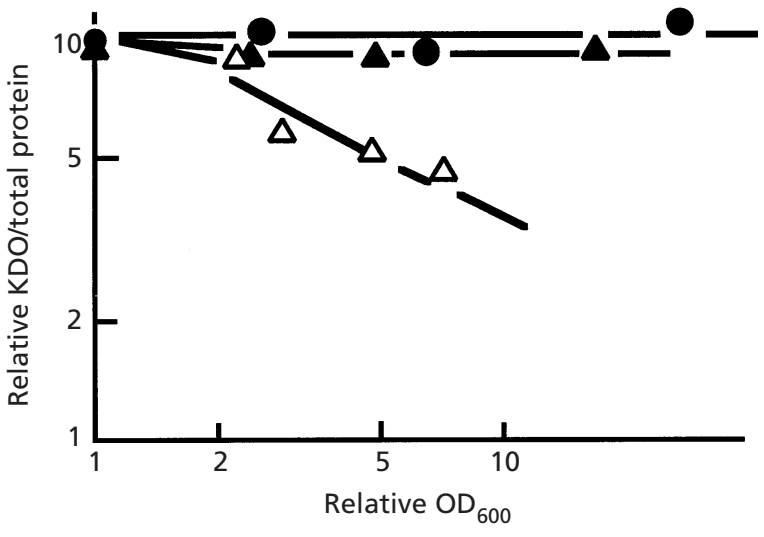

Fig. 6. Effect of $f t s 830$ on KDO synthesis. JE10830 ( $\triangle$ ), JE10830 transformed by a plasmid-borne wild-type $k d s A$, fts830/p $\left(k d s A^{+}\right)$ $(\boldsymbol{\Delta})$, and the parent (PA3092; $)$ ) cells growing exponentially at $30^{\circ} \mathrm{C}$ were diluted 1 - to 150 -fold with fresh medium and incubated at $41{ }^{\circ} \mathrm{C}$ for $0.5,1,2$ and $3 \mathrm{~h}$, respectively. For $\mathrm{fts} 830 / \mathrm{p}\left(k d s A^{+}\right), 10 \mu \mathrm{M}$ IPTG was added at time zero. $\mathrm{OD}_{600}$ was monitored at each time interval and cells were harvested and used for measuring KDO concentrations. The values of $\mathrm{OD}_{600}$ were corrected for the dilution factors and are shown relative to $0 \mathrm{~h}$. The relative amounts of KDO were plotted against the relative amount of $\mathrm{OD}_{600}$.

and $1 \mu \mathrm{l}$ was spotted onto LB agar containing varying concentrations of substances that destabilize, including SDS, eosin Y, EDTA and methylene blue. These cultures were incubated at $36{ }^{\circ} \mathrm{C}$ for $36 \mathrm{~h}$. JE10830 was highly sensitive to eosin $\mathrm{Y}$ and SDS; the minimum concentration of eosin $\mathrm{Y}$ and SDS inhibiting colony-forming ability at $36^{\circ} \mathrm{C}$ in JE10830 was $0.1 \%$ and $1 \%$, respectively, whilst that in PA3092 was more than $0.5 \%$ and $4 \%$, respectively. The mutant was less sensitive to EDTA than the wild-type strain; JE10830 was sensitive up to $10 \mathrm{mM}$ EDTA while PA3092 was sensitive up to $8 \mathrm{mM}$. On the contrary, the colony-forming ability of JE10830 was enhanced by the addition of methylene blue; JE10830 colony size increased with the addition of $0 \cdot 01 \%$ methylene blue whilst PA3092 colony size decreased compared to the control at $36^{\circ} \mathrm{C}$. Although JE10830 did not grow on $\mathrm{LB}$ medium without $\mathrm{NaCl}$ at $36{ }^{\circ} \mathrm{C}$, the addition of methylene blue restored growth under these conditions. Sensitivity to hydrophilic materials, such as kanamycin, was not altered by the mutation. These results suggest that the $k d s A$ mutation may cause instability in membrane structures, possibly affecting gene expression.

To confirm the relationship between instability of outer membrane and KDO synthesis, we examined the effect of $f t s 830$ on the synthesis of KDO. JE10830, the $k d s A$ transformant JE10830/p $\left(k d s A^{+}\right)$and their parent PA3092 cells, growing exponentially at $30^{\circ} \mathrm{C}$, were diluted in fresh medium and allowed to continue growing at $41^{\circ} \mathrm{C}$ for $0 \cdot 5,1,2$ or $3 \mathrm{~h}$. We monitored cell growth by measuring the $\mathrm{OD}_{600}$ and KDO concentrations were measured as described in Methods. As shown in Fig. 6, the specific content of KDO decreased approximately $75 \%$ for each doubling of the $\mathrm{OD}_{600}$ 

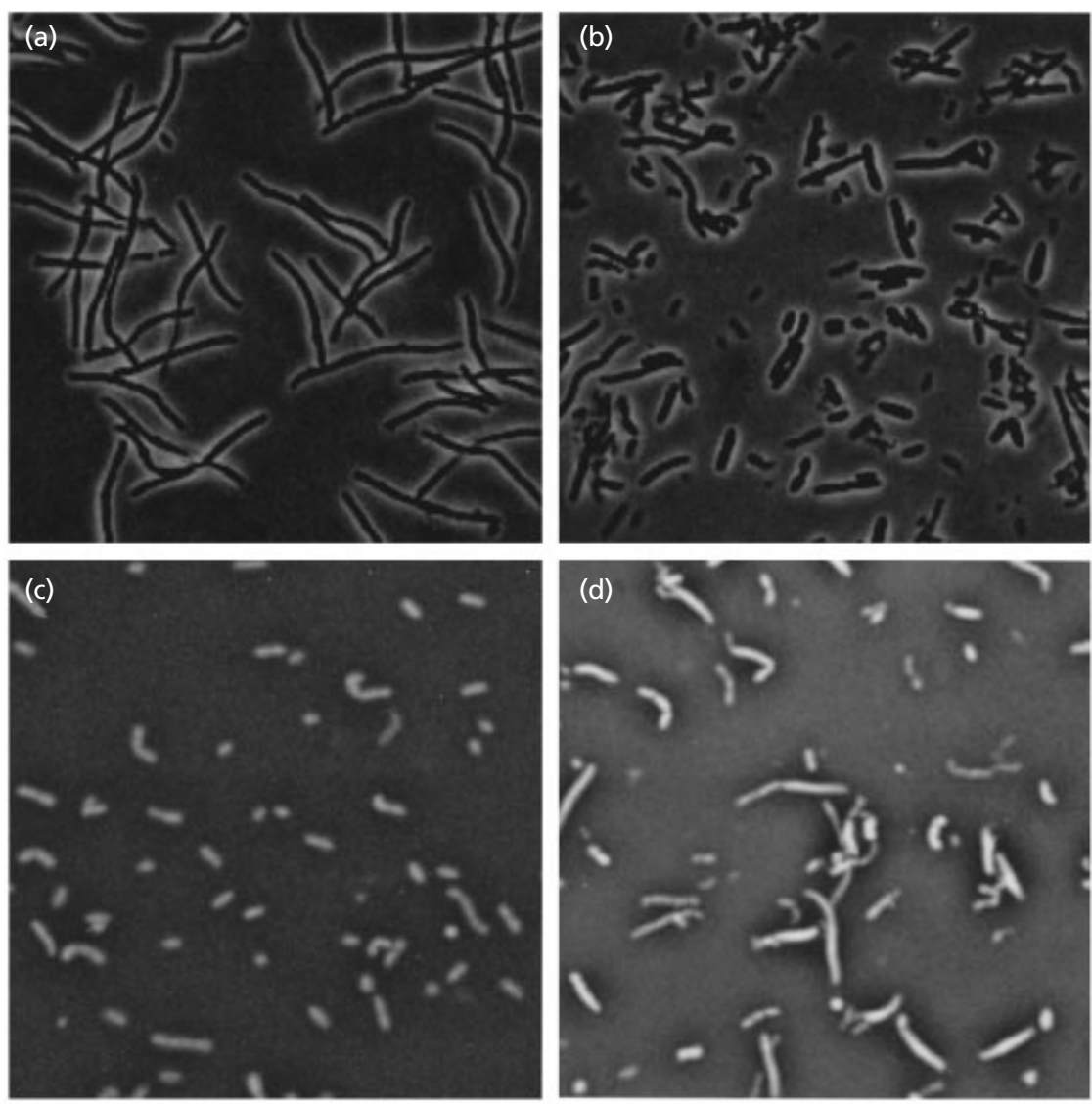

Fig. 7. Phase-contrast micrographs of JE10830/pMW118 (a) and JE10830/pMsbA (b) at $41{ }^{\circ} \mathrm{C}$, and the IpxA mutant, SM101, grown at either 30 (c) or $41^{\circ} \mathrm{C}(\mathrm{d})$. value. The plasmid carrying the wild-type $k d s A$ restored the specific content of KDO in the mutant cells to a level equal to that of the parent. These results indicate that the defect in KDO synthesis in JE10830 causes the instability of the outer membrane.

The $h \operatorname{tr} B$ gene encodes KDO-dependent lauroyltransferase and a defect in $h t r B$ causes the accumulation of lipid A (Clementz et al., 1996). Enhanced export of lipid A precursors mediated by extra copies of $m s b A$ permits cell growth in the $h \mathrm{trB}$ mutant (Karow \& Georgopoulos, 1993; Zhou et al., 1998). Therefore, we also examined whether the defects in $f t s 830 / k d s A$ could be corrected by plasmid-borne wild-type msbA. As shown in Fig. $7(\mathrm{a}, \mathrm{b})$, cell length of the mutant harbouring the $m s b A$ plasmid JE10830/pMsbA was apparently shorter than that of the mutant harbouring only vector, JE10830/pMW118, at $41{ }^{\circ} \mathrm{C}$. The growth defect of JE10830 was also corrected by transformation of pMsbA; the growth rate of JE10830/pMsbA was higher than that of JE10830/pMW118. The colonyforming ability of JE10830 was not restored, however. The result demonstrates that the defect in the cell division of JE10830 is corrected by the extra copies of wild-type $m s b A$, and the growth defect of JE10830 is alleviated partially, although colony-forming ability is not recovered.

To investigate whether the accumulation of lipid A precursors in the cytoplasmic membrane or the in- stability of the outer membrane affects cell division, we examined the effect of the $l p x A$ mutation on cell division. $\ln x A$ functions at the first stage in lipid A biosynthesis (Raetz, 1986), so lipid A is not synthesized in these mutants. Cells of an $l p x A$ mutant, SM101, growing exponentially at $30^{\circ} \mathrm{C}$, were diluted in fresh medium, allowed to continue growing at $41^{\circ} \mathrm{C}$ for $3 \mathrm{~h}$ and observed by phase-contrast microscopy. The $\ln x A$ mutation apparently affected cell division at $41^{\circ} \mathrm{C}$ (Fig. $7 \mathrm{c}, \mathrm{d})$, although the resulting filaments were very short because the mutation also affected cell growth severely. The cells were very thick and many ghost cells were found, indicating the instability of the membrane.

\section{The $k d s A$ mutations affect FtsZ-ring formation but not the production of FtsZ}

The seven mutants examined in this study did not demonstrate constriction at the potential division site (Fig. 2), suggesting cell division was inhibited at an early step. We therefore analysed the effect of the fts 830 mutation on FtsZ-ring formation by immunofluorescence microscopy using an anti-FtsZ antibody. As shown in Fig. 8, although the cell length of JE10830 continued to increase after temperature shift, the FtsZ ring increased marginally. After $3 \mathrm{~h}$ incubation at $41^{\circ} \mathrm{C}$, $65 \%$ of the cells contained only one FtsZ ring at one end of the filaments and the remaining $35 \%$ did not have an FtsZ ring. The ftsI mutant, RP41, contained FtsZ rings, 


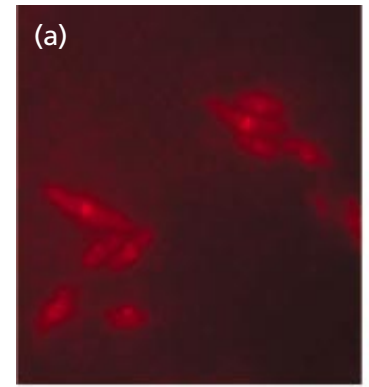

\section{(d)}
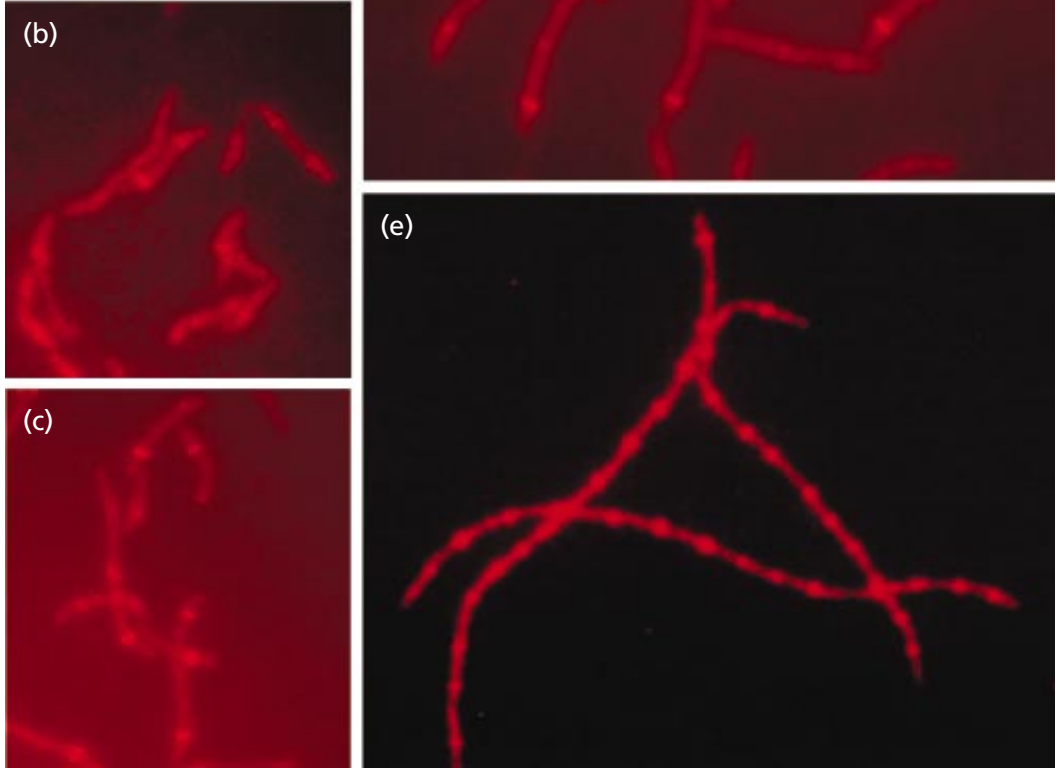

Fig. 8. FtsZ-ring localization in $\mathrm{fts} 830$ and $\mathrm{ftsl}$ cells. Immunofluorescence micrographs of JE10830 (fts830) grown at 30 (a) or $41^{\circ} \mathrm{C}$ for 1 (b), 2 (c) or $3 \mathrm{~h}(\mathrm{~d})$, and RP41 (ftsl) (e) grown for $3 \mathrm{~h}$ at $41^{\circ} \mathrm{C}$.

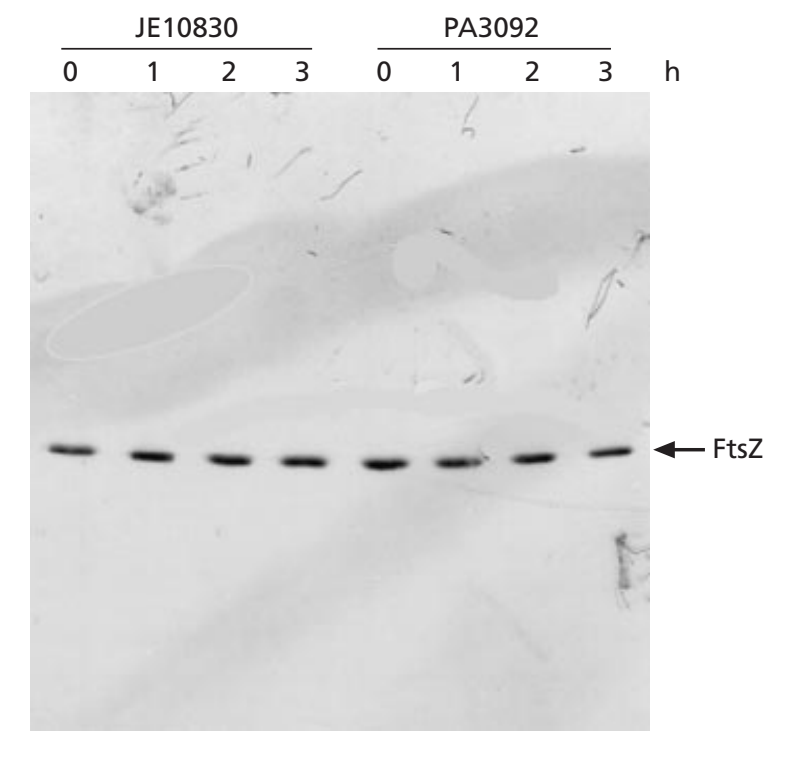

Fig. 9. Immunodetection of FtsZ by Western blotting in both JE10830 and the parent (PA3092) cells, grown at $41^{\circ} \mathrm{C}$ for $3 \mathrm{~h}$.

forming at almost all the potential division sites under the same experimental conditions. Therefore, the absence of FtsZ rings in JE10830 filaments is specific to the mutation.
A decrease in FtsZ to $60-70 \%$ of normal levels results in the inhibition of cell division (Dai \& Lutkenhaus, 1991). We also examined the total levels of FtsZ in whole cells. Both JE10830 and the parent cells were cultured as in the above experiment, then the total amounts of FtsZ were measured by Western blotting. The levels of FtsZ in the mutant cells did not change with increasing time of incubation at $41^{\circ} \mathrm{C}$, similar to the parent (Fig. 9). These data indicate that the $k d s A$ mutation affects FtsZ-ring formation, but does not affect the production of FtsZ.

\section{DISCUSSION}

$k d s A$ mutations not only affect the production of KDO and stability of the outer membrane, but also have profound effects on cell division. The cell division defect is caused by deficiencies in FtsZ-ring formation. A plasmid, carrying the wild-type $k d s A$, reversed all observed defects: KDO production, cell division and cell growth at $41{ }^{\circ} \mathrm{C}$. Therefore, we conclude that decreases in LPS synthesis affect FtsZ-ring formation, resulting in aberrant cell division. Western blotting demonstrated that $k d s A 830$ ( $f t s 830$ ) did not affect FtsZ production, however.

We concluded that instability of the outer membrane, due to a defect in the synthesis of complete LPS molecules, affects cell division. Complete LPS molecules may be required for some essential physiological func- 
tion of the outer membrane or assembly of a functional outer membrane. Rick \& Osborn (1977) also demonstrated in S. typhimurium that a defect in KDO synthesis causes pleiotropic effects on growth, LPS synthesis and accumulation of lipid A precursor in the isolated cytoplasmic membrane (Osborn et al., 1980). A defect in $h \operatorname{tr} B$, encoding KDO-dependent lauroyltransferase which acts after KDO addition during lipid A biosynthesis (Clementz et al., 1996), also inhibits cell division, producing filamentous cells at the non-permissive temperature, and inhibition of cell division of the $h \operatorname{tr} B$ mutant is suppressed by $m s b A$ which may encode an ATP-dependent translocator (Karow \& Georgopoulos, 1993). It is proposed that accumulation of lipid A precursors is toxic to cell growth (Rick \& Young, 1982) and that enhanced export of these precursors mediated by extra copies of $m s b A$ may permit cell growth (Zhou et al., 1998). The defect in cell division of JE10830 is also suppressed by the presence of extra copies of $m s b A$. The defect in colony-forming ability, however, was not suppressed at all. Moreover, a mutant of $\operatorname{lp} x A$, functioning at the first stage in lipid A biosynthesis to affect LPS synthesis (Raetz, 1986), also inhibits cell division in E. coli, producing short filamentous cells, although the growth was very poor at the restricted temperature. Our results, therefore, demonstrate that the inhibition of cell division by the $k d s A$ mutation is not caused by the accumulation of lipid A in the inner membrane. It seems more likely that the presence (or indeed the transport) of the lipid A precursor to the outer membrane may be essential for the stability of this membrane and that its instability in turn affects cell division.

The loss of LPS during KDO deficiency destabilizes the membrane structure, presumably causing large abnormalities in both the localization of membrane proteins and cell division. We observed a deficiency of FtsZ rings in the JE10830 filaments, although the levels of FtsZ were not affected by the mutation. The FtsZ ring, however, is constructed onto the inner membrane, maintaining a position at the leading edge of the invaginating septum (Bi \& Lutkenhaus, 1991; Sun et al., 1998 ) and the protein(s) governing this cell division at the outer membrane have not been found as yet. The mechanism whereby the instability of the outer membrane results in the loss of FtsZ-ring formation, therefore, remains to be established.

One of the possible explanations is that the instability of the outer membrane might affect the transcription of a cell division gene(s), required for FtsZ-ring formation. The outer membrane functions to communicate information received from the external environment into the cell. Therefore, membrane instability is expected to affect the transcription of genes, including those involved in cell division. We analysed the effect on membrane stability by examining the sensitivity of mutants to various hydrophobic materials. The results demonstrated that although the mutants were more susceptible to various hydrophobic materials, some hydrophobic materials restored $k d s A$ mutant growth, indicating that the instability of the outer membrane creates the altered cellular responses to the environment. Null mutations in either $h t r B$ or $m s b B$ also enable growth on four times the concentration of deoxycholate relative to wild-type bacteria (Karow \& Georgopoulos, 1993). Destabilization of the outer membrane may result in the expression of a subset of genes overcoming the sensitivity to the hydrophobic materials.

LPS comprises approximately $30 \%$ of the outer membrane in gross weight (Leive, 1974). Therefore, decreases in LPS may destabilize the outer membrane and may expose phospholipids to the external environment. Phospholipids are integral in the regulation of cell cycle, and interruptions of phospholipid synthesis inhibit both the initiation of chromosome replication and cell division (Norris, 1989). In addition, the physical nature of phospholipids changes dramatically with various growth conditions (Tilcock, 1986). Phospholipids are also important in the transfer of signals from the extracellular environment to the replication and transcription machinery (Sekimizu, 1994). Therefore, loss of LPS may change the physical nature of phospholipids due to exposure to their surroundings, altering the expression of various genes. In S. typhimurium, the rate of OmpA synthesis is proposed to be activated by the $k d s A$ mutation (Rick et al., 1983, 1984), although the mechanism of this activation is not well understood.

All six mutations analysed in this article concerned nonpolar amino acids of which four were replaced by polar ones. Mutations substituting these amino acids inhibited cell division severely, except fts1167. Recently, the crystal structure of KdsA was determined by Radaev et al. (2000). The unit cell of the crystal consists of a homotetramer of KdsA. The six mutation sites are not localized in space, but are scattered throughout the three-dimensional structure: two sites, Leu 118 ( $f t s 705$ ) and Ala 227 ( $f$ ts1212), were located on the monomermonomer interfaces making contacts between the same residues, Leu-Leu and Ala-Ala, of different subunits, and thus might affect the stability of tetramer complexes. Ala 203 (fts446) is close to His 202, which is one of the binding sites of phosphoenolpyruvate (Radaev et al., 2000), and thus might disturb catalytic activity of KdsA. Gly 73 ( $f$ ts 830 and $f t s 1241$ ), sitting at the start of an $\alpha$ helix, has a positive phi-angle, which is allowed for Gly but may not be adequate for other amino acids such as Asp. Ala 14 ( fts1167) and Ala 234 (fts1171) are close to each other in space, suggesting similar effects if any, whereas we cannot see any definite reason for instability caused by mutations at these sites. These data suggest that the reduction of catalytic activity of KdsA might result from the instability of three-dimensional structures at high temperature, rather than any direct effects on the active centre of the enzyme.

\section{ACKNOWLEDGEMENTS}

We are grateful to Dr Joe Lutkenhaus who kindly provided anti-FtsZ polyclonal antibody. We also thank Dr Koichi Inouye who kindly advised on the technique for the quan- 
titative analysis of KDO. This work was supported by a Grant-in-Aid for Scientific Research on Priority Areas (A), from the Ministry of Education, Culture, Sports, Science and Technology of Japan.

\section{REFERENCES}

Addinall, S. G., Bi, E. \& Lutkenhaus, J. (1996). FtsZ ring formation in fts mutants. J Bacteriol 178, 3877-3884.

Bi, E. F. \& Lutkenhaus, J. (1991). FtsZ ring structure associated with division in Escherichia coli. Nature 354, 161-164.

Buxton, R. S. \& Holland, I. B. (1973). Genetic studies of tolerance to colicine E2 in Escherichia coli K-12. I. Relocation and dominance relationships of cet mutations. Mol Gen Genet 127, 69-88.

Clarke, L. \& Carbon, J. (1976). A colony bank containing synthetic ColE1 hybrid plasmids representative of entire E. coli genome. Cell 9, 91-99.

Clementz, T., Bednarski, J. \& Raetz, C. R. H. (1996). Function of the $h t r B$ high temperature requirement gene of Escherichia coli in the acylation of lipid A. J Biol Chem 271, 12095-12102.

Dai, K. \& Lutkenhaus, J. (1991). FtsZ is an essential cell division gene in Escherichia coli. J Bacteriol 173, 3500-3506.

Drlica, K. (1984). Biology of bacterial deoxyribonucleic acid topoisomerases. Microbiol Rev 48, 273-289.

Hancock, R. E. W. \& Reeves, P. (1976). Lipopolysaccharidedeficient, bacteriophage-resistant mutants of Escherichia coli K12. J Bacteriol 127, 98-108.

Hiraga, S., Niki, H., Ogura, T., Ichinose, C., Mori, H., Ezaki, B. \& Jaffé, A. (1989). Chromosome partitioning in Escherichia coli: novel mutants producing anucleate cells. J Bacteriol 171, 14961505 .

Hiraga, S., Ichinose, C., Niki, H. \& Yamazoe, M. (1998). Cell cycledependent duplication and bidirectional migration of SeqAassociated DNA-protein complexes in E. coli. Mol Cell 1, 381-387.

Karkhanis, Y. D., Zeltner, J. Y., Jackson, J. J. \& Carlo, D. J. (1978). A new and improved microassay to determine 2-keto-3-deoxyoctonate in lipopolysaccharide of gram negative bacteria. Anal Biochem 85, 595-601.

Karow, M. \& Georgopoulos, C. (1993). The essential Escherichia coli msbA gene, a multicopy suppressor of null mutations in the $h \operatorname{tr} B$ gene, is related to the universally conserved family of ATPdependent translocators. Mol Microbiol 7, 69-79.

Lehmann, V., Rupprecht, E. \& Osborn, M. J. (1977). Isolation of mutants conditionally blocked in the biosynthesis of 3-deoxy-Dmanno-octulosonic acid-lipid A part of lipopolysaccharides derived from Salmonella typhimurium. Eur J Biochem 76, 41-49.

Leive, L. (1974). The barrier function of the gram negative envelope. Ann NY Acad Sci 235, 109-129.

Nagai, K. \& Tamura, G. (1972). Mutant of Escherichia coli with thermosensitive protein in the process of cellular division. $J$ Bacteriol 112, 959-966.

Nikaido, H. \& Vaara, M. (1985). Molecular basis of bacterial outer membrane permeability. Microbiol Rev 49, 1-32.

Nishimura, A., Akiyama, K., Kohara, Y., Takeda, Y., Nishimura, Y., Higashitani, A., Yasuda, S., Horiuchi, K. \& Hirota, Y. (1991). Mapping of a whole set of cell division genes in Escherichia coli K-12. In Control of Cell Growth and Division, pp. 205-223. Edited by A. Ishihama \& H. Yoshikawa. Tokyo: Japan Science Society Press/Berlin: Springer.

Nishimura, A., Akiyama, K., Kohara, Y. \& Horiuchi, K. (1992).
Correlation of a subset of the pLC plasmids to the physical map of Escherichia coli K-12. Microbiol Rev 56, 137-151.

Norris, V. (1989). Phospholipid flip-out controls the cell cycle of Escherichia coli. J Theor Biol 139, 117-128.

Osborn, M. J., Rick, P. D. \& Rasmussen, N. S. (1980). Mechanism of assembly of the outer membrane of Salmonella typhimurium. Translocation and integration of an incomplete mutant lipid A into the outer membrane. J Biol Chem 255, 4246-4251.

Radaev, S., Dastidar, P., Patel, M., Woodard, R. W. \& Gatti, D. L. (2000). Structure and mechanism of 3-deoxy-D-manno-octulosonate 8-phosphate synthase. J Biol Chem 275, 9476-9484.

Raetz, C. R. H. (1986). Molecular genetics of membrane phospholipid synthesis. Annu Rev Genet 20, 253-295.

Raetz, C. R. H., Purcell, S., Meyer, M. V., Qureshi, N. \& Takayama, K. (1985). Isolation and characterization of eight lipid A precursors from a 3-deoxy-D-manno-octulosonic acid-deficient mutant of Salmonella typhimurium. J Biol Chem 260, 16080-16088.

Ray, P. H. (1980). Purification and characterization of 3-deoxy-Dmanno-octulosonate-8-phosphate synthetase from Escherichia coli. J Bacteriol 141, 635-644.

Reeves, J. D., Groves, D. \& Clark, D. J. (1970). Regulation of cell division in Escherichia coli: characterization of temperaturesensitive division mutants. J Bacteriol 104, 1052-1064.

Ricard, M. \& Hirota, Y. (1973). Effect osmotique sur le phénotype de mutants thermosensibles d'E. coli. Ann Inst Pasteur 124, 29-43.

Rick, P. D. \& Osborn, M. J. (1977). Lipid A mutants of Salmonella typhimurium. Characterization of conditional lethal mutant in 3deoxy-D-manno-octulosonate-8-phosphate synthetase. J Biol Chem 252, 4895-4903.

Rick, P. D. \& Young, D. A. (1982). Isolation and characterization of a temperature-sensitive lethal mutant of Salmonella typhimurium that is conditionally defective in 3-deoxy-D-mannooctulosonate-8-phosphate synthetase. J Bacteriol 150, 447-455.

Rick, P. D., Fung, L. W. M. \& Osborn, M. J. (1977). Lipid A mutants of Salmonella typhimurium. Purification and characterization of a lipid A precursor produced by a mutant in 3-deoxy-D-mannooctulosonate-8-phosphate synthetase. J Biol Chem 252, 49044912.

Rick, P. D., Neumeyer, B. A. \& Young, D. A. (1983). Effect of altered lipidA synthesis on the synthesis of the OmpA protein in Salmonella typhimurium. J Biol Chem 258, 629-635.

Rick, P. D., Neumeyer, B. A. \& Young, D. A. (1984). Effect of altered lipid A synthesis on the synthesis of major proteins of the Salmonella typhimurium outer membrane. Rev Infect Dis 6, 455-462.

Rietschel, E. T. (editor) (1984). Chemistry of endotoxin. Handbook of Endotoxin, Vol. 1. Amsterdam: Elsevier.

Sambrook, J., Fritsch, E. F. \& Maniatis, T. (1989). Molecular Cloning: a Laboratory Manual, 2nd edn. Cold Spring Harbor, NY : Cold Spring Harbor Laboratory.

Sekimizu, K. (1994). Interactions between DNA replicationrelated proteins and phospholipid vesicles in vitro. Chem Phys Lipids 73, 223-230.

Smit, J., Kamio, Y. \& Nikaido, H. (1975). Outer membrane of Salmonella typhimurium: chemical analysis and freeze-fracture studies with lipopolysaccharide mutants. J Bacteriol 124, 942-958.

Strohmaier, H., Remler, P., Renner, W. \& Högenauer, G. (1995). Expression of genes $k d s A$ and $k d s B$ involved in 3-deoxy-Dmanno-octulosonic acid metabolism and biosynthesis of enterobacterial lipopolysaccharide is growth phase regulated primarily 
at the transcriptional level in Escherichia coli K-12. J Bacteriol 177, 4488-4500.

Sun, Q., Yu, X. C. \& Margolin, W. (1998). Assembly of the FtsZ ring at the central division site in the absence of the chromosome. Mol Microbiol 29, 491-503.

Tilcock, C. P. S. (1986). Lipid polymorphism. Chem Phys Lipids 40, 109-125.

Wilson, G. G., Young, K. K. Y. \& Edlin, G. J. (1979). Highfrequency generalized transduction by bacteriophage T4. Nature 280, 80-82.
Woisetschläger, M. \& Högenauer, G. (1987). The $k d s A$ gene for 3deoxy-D-manno-octulosonate-8-phosphate synthetase is part of an operon in Escherichia coli. Mol Gen Genet 207, 369-373.

Zhou, Z., White, K. A., Polissi, A., Georgopoulos, C. \& Raetz, C. R. H. (1998). Function of Escherichia coli MsbA, an essential ABC family transporter, in lipid A and phospholipid biosynthesis. J Biol Chem 273, 12466-12475.

Received 25 May 2001; revised 7 August 2001; accepted 25 September 2001. 